\title{
EL PRINCIPIO DE PUBLICIDAD REGISTRAL Y SUS MANIFESTACIONES: ESPECIAL ATENCIÓN A SU DIMENSIÓN FORMAL Y A LA INCIDENCIA DE LOS DERECHOS FUNDAMENTALES EN SU CONFIGURACIÓN
}

The principle of registration advertising and its manifestations: special attention to its formal dimension and the impact of fundamental rights in its configuration

MANUEL ORTIZ FERNÁNDEZ Universidad Miguel Hernández de Elche m.ortizf@umh.es

\section{Resumen}

El Registro de la Propiedad es un organismo público en el que se inscriben los actos y contratos relativos al dominio y demás derechos reales sobre bienes inmuebles. Su función principal es ofrecer seguridad jurídica al tráfico inmobiliario y viene expresada en las dos manifestaciones del principio de publicidad registral, a saber, la vertiente material y la vertiente formal. No obstante, las normas reguladoras del ámbito registral han de ser interpretadas desde una perspectiva constitucional, ya que algunas medidas aprobadas a su amparo pueden suponer una conculcación de ciertos derechos fundamentales. En particular, este aspecto puede producirse cuando nos 
referimos a la dimensión formal del Registro y a algunos de los derechos previstos en el art. 18 de la Constitución española: el honor, la intimidad y la protección de datos.

\title{
Palabras clave
}

Derechos; principios; publicidad; registral; seguridad.

\begin{abstract}
The Property Registry is a public body that registers acts and contracts relating to the domain and other rights in real property. Its main function is to provide legal certainty to real estate trafficking and is expressed in the two manifestations of the principle of registration advertising, namely the material aspect and the formal aspect. However, the rules regulating the registration area must be interpreted from a constitutional perspective, since some measures adopted under it may constitute a violation of certain fundamental rights. In particular, this aspect can occur when we refer to the formal dimension of the registry when we refer to the formal dimension of the Registry and some of the rights provided for in article 18 of the Spanish Constitution: honor, privacy and data protection.
\end{abstract}

\section{Keywords}

Rights; principles; advertising; register; security. 


\section{SUMARIO}

I. INTRODUCCIÓN. II. LOS DERECHOS REALES Y LOS PRINCIPIOS REGISTRALES: LAS MEDIDAS CAUTELARES COMO MEDIO PARA REALIZAR ANOTACIONES. III. BREVE REFERENCIA AL PRINCIPIO DE PUBLICIDAD MATERIAL: LA FIGURA DEL «TERCERO HIPOTECARIO»Y LA PROTECCIÓN EX POST. IV. EL PRINCIPIO DE PUBLICIDAD FORMAL Y LOS DERECHOS FUNDAMENTALES PREVISTOS EN EL ART. 18 CE: LA PROTECCIÓN EX ANTE Y SU REVISIÓN CONSTITUCIONAL:

1. Breve referencia a la configuración de los derechos al honor, la intimidad y la protección de datos: conceptos y características esenciales: 1.1. El derecho al honor. 1.2. El derecho a la intimidad. 1.3. El derecho a la protección de datos. 2. La colisión entre derechos y el principio de proporcionalidad frente a la adecuada delimitación de sus contornos: 2. 1. La solución adoptada en la STC 28/2020, de 24 de febrero. 2.2. Revisión de la STC 28/2020, de 24 de febrero: otros derechos implicados y criterio de la delimitación de derechos. BibLIOGRafía.

\section{INTRODUCCIÓN}

El Registro de la Propiedad es un organismo público en el que se inscriben los actos y contratos relativos al dominio y demás derechos reales sobre bienes inmuebles (art. 605 CC y art. 1.1 Decreto de 8 de febrero de 1946 por el que se aprueba la nueva redacción oficial de la Ley Hipotecaria, en adelante, LH). Se trata, por tanto, de una institución jurídica destinada a «robustecer la seguridad en el tráfico inmobiliario mediante la publicación del estado jurídico de los inmuebles» ${ }^{1}$. En definitiva, al citado Registro se le pueden atribuir dos funciones o dos ámbitos de aplicación que aparecen expresados en las dos dimensiones del principio de publicidad, a saber, la vertiente material y la vertiente formal. De un lado, el primero se refiere a la tutela que se ofrece a las facultades de los titulares de los derechos reales inscritos en la medida en que se encuentran amparados por las presunciones correspondientes. De otro lado, el segundo se centra en favorecer la seguridad jurídica y proteger los derechos de terceros en tanto en cuanto pueden conocer la verdadera situación de los bienes y el patrimonio inmobiliario de la persona.

1 En este sentido, véase De Reina Tartière (2012: 50). 
No obstante, como se verá, se encuentran íntimamente ligados y aparecen como dos partes de una misma realidad.

Sin embargo, las anteriores premisas han de ser observadas desde una perspectiva constitucional, tratando de adaptar la normativa a los mandatos de la Carta Magna. A este respecto, es necesario que nos refiramos a los derechos fundamentales que se reconocieron tras la aprobación y entrada en vigor de la Constitución Española (arts. 15 a $29 \mathrm{CE}^{2}$ ). Estos últimos pasaron a gozar de una especial protección y esta tutela se tradujo, principalmente, en la reserva de ley orgánica para su posible desarrollo y en el acceso al recurso de amparo ante el Tribunal Constitucional. En particular, en este ámbito adquieren especial relevancia los derechos al honor, intimidad y protección de datos recogidos en el art. $18 \mathrm{CE}$.

Precisamente sobre estas cuestiones se ha manifestado la reciente STC 28/2020, de 24 febrero $^{3}$, en la que el Tribunal Constitucional se ha planteado si la aprobación de una medida cautelar real en el marco de un procedimiento penal, pero con incidencia en el ámbito civil, puede suponer una violación del derecho al honor del titular. En concreto, se trataba de una anotación en el Registro de la Propiedad relativa a la prohibición de disponer de los inmuebles por parte de su titular. En realidad, como más tarde se tendrá ocasión de comprobar, el demandante de amparo no formuló objeción a la medida, en sí misma considerada, sino a la forma en que se había llevado a cabo. Así, entendió que la inclusión en el Registro de los presuntos delitos cometidos resultaba innecesaria y constituía una infracción del mencionado derecho al honor.

\section{LOS DERECHOS REALES Y LOS PRINCIPIOS REGISTRALES: LAS MEDIDAS CAUTELARES COMO MEDIO PARA REALIZAR ANOTACIONES}

Como se ha indicado, el Registro de la Propiedad tiene como finalidad ofrecer seguridad en el tráfico inmobiliario. Fundamentalmente, la principal

2 Cabría, no obstante, anudar otros derechos recogidos en diversos preceptos como el art. $10 \mathrm{CE}$ (referido a la dignidad), el art. $14 \mathrm{CE}$ (que se centra en la igualdad ante la ley y la prohibición de discriminación) o el art. 30.2 CE (que se ocupa de la objeción de conciencia). Asimismo, debemos aludir a la práctica frecuente de añadir «nuevos» derechos fundamentales que, sin estar previstos en la Constitución, han pasado a gozar de una protección especial para la doctrina científica. Sobre el particular, véase Hermida del Llano et al. (2015).

3 RTC 2020\28. 
ventaja que se deriva de la inscripción de un bien inmueble en el Registro es la publicidad que otorga frente a terceros y la presunción de buena fe del adquirente del citado bien. Como se puede comprobar, el mismo dispone de una doble vertiente o dos ámbitos de actuación: de un lado, sirve para tutelar los propios derechos de los titulares y, de otro lado, permite que terceros implicados conozcan el verdadero estado del bien, con lo que se salvaguardan sus posibles intereses o facultades.

Así, se suele aludir a los principios registrales que, sin ser verdaderas fuentes del derecho registral, suponen una síntesis técnica del ordenamiento jurídico hipotecario. No obstante, para comprenderlos adecuadamente se han de interpretar conjuntamente, de tal suerte que no debemos entenderlos de forma independiente. En este sentido y, a pesar de las múltiples clasificaciones que se han propuesto ${ }^{4}$, consideramos que la más conveniente es la que se refiere al principio de publicidad como la base que engloba al resto de principios. Al mismo se le atribuyen dos perspectivas o realidades (relacionadas, a su vez, con las vertientes mencionadas del Registro).

Por un lado, encontramos la publicidad material que incluye, a su vez, dos dimensiones. En primer lugar, la negativa (que se puede deducir del art. $32 \mathrm{LH}$ ) implica que los títulos no inscritos no pueden afectar a otros que sí lo están o, en otras palabras, que se otorga protección a estos últimos frente a los primeros (principio de inscripción). En segundo lugar, la positiva (art. $38 \mathrm{LH}$ ) se concreta en la presunción iuris tantum de veracidad del contenido registral (con lo que se identifica con el principio de legitimación) y en la presunción de la exactitud e integridad de la inscripción (equivalente al principio de fe pública registral). Por otro lado, la publicidad formal alude a la notoriedad y conocimiento, por parte de terceros, de las inscripciones efectuadas en el Registro (art. $221 \mathrm{LH})$.

Con todo, pueden producirse situaciones conflictivas derivadas de la propia configuración del mismo ${ }^{5}$. Así las cosas, entendemos que debemos

4 Así, se suele diferenciar entre principios referidos a los efectos de la inscripción y principios centrados en los requisitos de dicha inscripción. En cuanto a los primeros, encontramos los de inscripción, legitimación, inoponibilidad, fe pública y prioridad. Por su parte, entre los segundos se ubican los de rogación, especialidad, tracto sucesivo y legalidad (titulación pública y calificación). Con todo, no son principios absolutos y admiten excepciones. A modo de ejemplo, en algunos casos las inscripciones en el Registro no provienen de una petición de la parte interesada (rogación), sino que su origen es judicial. De todos ellos, quizá son más interesantes, a los efectos comentados, los de legalidad y legitimación.

5 La problemática relativa al principio de publicidad se remonta al siglo XVII, en el que, parte de la doctrina data el inicio de este principio. De alguna forma, el impulso del 
diferenciar entre dos tipos de problemáticas que, además, coinciden con las dos dimensiones del principio citado. De un lado, en el ámbito del principio de publicidad material encontramos casos en los que, por ejemplo, se produce una doble enajenación de un bien inmueble, situación que se ha de resolver desde una lógica específica. En definitiva, se trata de supuestos en los que los regímenes de los derechos reales y del derecho registral pueden aparecer enfrentados y en los que se ha de escoger entre dos pretensiones, en principio, dignas de protección. En estos escenarios, se otorga cierta preferencia a los derechos que figuran en el Registro de Propiedad ofreciendo, pues, un tratamiento diferenciado. Por su parte, la extensión excesiva del principio de publicidad formal puede desembocar en contextos poco deseables (ya por el número de personas que tengan acceso sin fundamento para ello, ya por la relevancia de los datos que se compartan) y es necesario reflexionar a este respecto.

No obstante, ambos se encuentran íntimamente ligados, como se tendrá ocasión de comprobar, ya que su fundamento es similar. Y es que, en realidad, estos principios se retroalimentan y complementan mutuamente, pues el principio de publicidad formal trata de evitar que se produzcan conflictos que se pueden plantear en el ámbito del principio de publicidad material. Por ello, han de ser examinados como las "caras» de una misma moneda. En este sentido, en los dos el debate gira en torno a la mencionada seguridad del tráfico ${ }^{6}$ y la posible afectación del mercado. Más tarde volveremos sobre estas disquisiciones.

Para finalizar con este apartado, hemos de referirnos a la viabilidad de que las anotaciones en el Registro se produzcan como consecuencia de un procedimiento judicial y, en especial, por aplicación de una medida cautelar ${ }^{7}$. Conviene destacar que la finalización normal de un procedimiento es la emisión de una sentencia, ya sea estimatoria o no de la pretensión formulada. No obstante, lo cierto es que podemos encontrar circunstancias que, de algún modo, frustren el resultado del potencial fallo judicial. En este sentido, a nadie se le escapa que este extremo es injusto y que vacía de contenido la facultad del juez, en tanto en cuanto no permite que la parte que obtiene un resultado favorable tras el pleito ejecute lo acordado por el tribunal. Precisamente para tratar de paliar estas circunstancias, el ordenamiento jurídico español prevé

mercado siempre ha definido los contornos del derecho y ha incidido de forma directa en su contenido. Para más información, véase Valpuesta Fernández (2005: 1515).

6 A este respecto, García García (1994b: 2239-2310) pone de relieve la conexión que existe entre la seguridad jurídica inmobiliaria (ex art. $34 \mathrm{LH})$ y la seguridad jurídica prevista en el artículo $9 \mathrm{CE}$ teniendo, además, la primera prevalencia sobre la segunda.

7 Por todos, véanse Fernández Ballesteros (2001); Garberí Llobregat (2016). 
las denominadas medidas cautelares, que permiten anticipar la intervención judicial para asegurar que se cumpla lo que, de forma probable, se dicte en el futuro pronunciamiento.

En este sentido, el Tribunal Constitucional ha destacado la vinculación entre las medidas cautelares y el derecho fundamental a la tutela judicial efectiva (art. 24.1 CE). Desde los inicios de los pronunciamientos de este Tribunal se aludió a esta premisa, entendiendo que existen supuestos en los que podría vulnerarse el precitado derecho al privar a los justiciables, de forma injustificada, de una garantía que se configura como contenido del mismo ${ }^{8}$. En este sentido, a pesar de que el art. 24.1 CE no se refiere a estas medidas ni a las potestades de suspensión:

[...] de ello no puede inferirse que quede libre el legislador de todo límite para disponer o no medidas de aquel género o para ordenarlas sin condicionamiento constitucional alguno. La tutela judicial ha de ser, por imperativo constitucional, «efectiva», y la medida en que lo sea o no ha de hallarse en la suficiencia de las potestades atribuidas por ley a los órganos del poder judicial para, efectivamente, salvaguardar los intereses o derechos cuya protección se demanda?

Estas medidas pueden acordarse tanto en los procesos civiles como en los penales ${ }^{10}$, siendo estas últimas las que han sido objeto de un estudio más exhaustivo ${ }^{11}$ porque pueden colisionar con los derechos fundamentales del

8 En este sentido, véase Fundamento Jurídico $7^{\circ}$ de la STC 14/1992, de 10 febrero (RTC 1992\14).

9 Véase Fundamento Jurídico 3o de la STC 238/1992, de 17 diciembre (RTC 1992 1238). Así, destaca esta última que: «La potestad jurisdiccional de suspensión, como todas las medidas cautelares, responde así a la necesidad de asegurar, en su caso, la efectividad del pronunciamiento futuro del órgano jurisdiccional: esto es, de evitar que un posible fallo favorable a la pretensión deducida quede (contra lo dispuesto en el art. 24.1 CE) desprovisto de eficacia por la conservación o consolidación irreversible de situaciones contrarias al derecho o interés reconocido por el órgano jurisdiccional en su momento".

10 En el ámbito penal, también se suele recurrir a medidas de este tipo y «puede inferirse que la finalidad a la que sirven las medidas cautelares forma parte de la función de juzgar y hacer ejecutar lo juzgado, y de igual modo se acepta que el sistema de medidas cautelares de la LECrim presente un marcado carácter garantista, es decir, esté previsto para garantizar la presencia del imputado en el juicio oral y para garantizar el cumplimiento efectivo de la sentencia». En este sentido, véase Chocrón Giráldez (2007: 2836).

11 Para más información al respecto, véanse Arias Grillo (2008: 77-110); Giner García (2014); Moreno Catena (2015: 173-202). 
investigado ${ }^{12}$. Así, a pesar de que el objetivo puede coincidir con el sector civil, en ciertos escenarios ${ }^{13}$ pueden verse comprometidos, directamente, los derechos del investigado y, por ello, se han de exigir unos requisitos determinados. De hecho, la doctrina penalista y procesalista advierte del peligro de la tendencia de incorporar nuevas medidas que han desdibujado el fin último de las mismas ${ }^{14}$.

En el supuesto de hecho planteado en la mencionada STC 28/2020, de 24 febrero, los tribunales acordaron practicar una anotación en el Registro de Propiedad relativa a la prohibición de disponer sobre los bienes allí incluidos por parte del investigado. Para llevar a cabo este extremo, se aplicó una interpretación de conjunto entre los arts. 764 LECrim y 727 LEC, en tanto se consideró que el primero de ellos remite a la posibilidad de imponer las medidas previstas en el segundo. En realidad, si se observa con detenimiento, nos encontramos ante una previsión que, si bien se incardina en el

12 Sin embargo, de ello no se sigue que las medidas cautelares aprobadas en el marco de un procedimiento civil o previstas en la Ley de Enjuiciamiento Civil no puedan producir un daño en ciertos derechos. En este sentido, es muy posible que se produzca una vulneración de ciertos derechos fundamentales como el honor, la intimidad, la propia imagen o la protección de datos personales, así como de otras facultades que, sin tener dicha categorización, son dignas de protección. A este respecto, nos podemos encontrar un supuesto en el que, por ejemplo, se conculque el derecho a la propiedad del titular por acordar el embargo de bienes de forma injustificada y desproporcionada.

Como se puede comprobar, nos encontramos ante unas disposiciones que dependen, de forma directa, del pleito principal y tratan de garantizar el resultado que, posiblemente, se dicte en la sentencia definitiva. Esta es la posición que adopta el legislador en el art. 728.1 LEC y, por este motivo, el apartado segundo del mencionado art. 728 CC exige que el solicitante presente «los argumentos y justificaciones documentales que conduzcan a fundar, por parte del Tribunal, sin prejuzgar el fondo del asunto, un juicio provisional e indiciario favorable al fundamento de su pretensión». Igualmente, con carácter general, deberá prestar caución suficiente para responder de los posibles daños y perjuicios derivados de la medida. De alguna forma, los requisitos exigidos por la norma pueden resumirse en tres: probabilidad de éxito de la pretensión formulada (apariencia de buen derecho); la prueba de que existe riesgo efectivo de que no se podrá ejecutar la sentencia (peligro por la mora procesal); y la prestación de una fianza que, eventualmente, se pueda emplear para reparar los daños producidos (caución).

13 Además, esta posibilidad no se prevé expresamente en el Real Decreto de 14 de septiembre de 1882 por el que se aprueba la Ley de Enjuiciamiento Criminal, al contrario de lo que ocurre con la Ley 1/2000, de 7 de enero, de Enjuiciamiento Civil. De hecho, la primera realiza una remisión en bloque en materia de medidas cautelares a la segunda.

14 En este sentido, véase Barona Vilar (2006: 237-265). 
seno de un juicio penal, tiene, indudablemente, tintes civiles. En este sentido, hemos de reparar en que la Ley 1/2000 dispone, al igual que ocurre con el derecho privado en general, de carácter subsidiario y supletorio con respecto al resto de ramas del ordenamiento jurídico. La apreciación operada por el tribunal resulta, a nuestro parecer, respetuosa con este último.

Conviene destacar que, además, el titular de los bienes inmuebles no era el investigado en la causa penal, sino que figuraban a nombre de una mercantil. No obstante, el órgano jurisdiccional entendió que la citada medida debe proyectarse sobre este sujeto por existir «indicios racionales de que el verdadero titular de los mismos es el encausado, haciéndolo constar así en el mandamiento» (art. $20 \mathrm{LH}$ ).

En este marco, el Tribunal Constitucional no cuestionó la legalidad y regularidad del auto que acordó esta medida, como tampoco lo realizó el demandante de amparo. No puede obviarse que, tal y como hemos destacado, la finalidad de las medidas cautelares es, precisamente, asegurar el cumplimiento de un futuro y probable pronunciamiento. Máxime porque en el caso se estimó que los inmuebles eran procedentes de los delitos imputados, a saber, contra la Hacienda Pública y de blanqueo de dinero.

Lo que se plantea es si, por el contrario, el contenido de la anotación de prohibición de disponer era respetuoso con los derechos del investigado y si, en definitiva, todos los datos incluidos eran necesarios para cumplir con el objetivo pretendido. A nuestros efectos, son especialmente relevantes las previsiones contenidas en los apdos. 5 y 6 del art. 727 LEC, ya que se centran en la anotación preventiva de demanda, cuando esta se refiera a bienes o derechos susceptibles de inscripción en registros públicos y en otras anotaciones registrales, en casos en que la publicidad registral sea útil para el buen fin de la ejecución. A este respecto, si lo que se busca es que dichos bienes no sean enajenados o donados por su titular, no puede negarse que, sin mencionar los presuntos delitos cometidos, se alcanzaría dicho fin. A modo de conclusión inicial, podemos indicar que, por tanto, no se encuentra justificada la medida en atención a los objetivos perseguidos por este tipo de prácticas. No obstante, es necesario que analicemos la cuestión desde otras perspectivas para concluir en un sentido u otro.

\section{BREVE REFERENCIA AL PRINCIPIO DE PUBLICIDAD MATERIAL: LA FIGURA DEL «TERCERO HIPOTECARIO» Y LA PROTECCIÓN EX POST}

De una parte, desde la perspectiva material de la publicidad, se han planteado distintos escenarios en los que pueden existir diferentes intereses 
contrapuestos. Es el caso de los denominados «terceros protegidos» o, si se quiere, "tercero hipotecario" y la interpretación que se ofrece a los arts. 32 y $34 \mathrm{LH}^{15}$. En suma, con ello se quiere hacer referencia a los sujetos que acceden al Registro y que, por tanto, consolidan una adquisición de un derecho real sobre un bien inmueble frente a aquellos que no han procedido en tal sentido pero que han adquirido un derecho real sobre el bien. Como pone de relieve la doctrina ${ }^{16}$, nuestro derecho "parte de la base de que la propiedad y los demás derechos reales se adquieren y se transmiten en virtud de ciertos contratos mediante la tradición; la inscripción es en general voluntaria, de forma que, en general, las modificaciones reales se producen al margen del Registro de la Propiedad, con lo cual hay una doble vida registral y extrarregistral».

Además, esta doble vida de los derechos reales «provoca, muchas veces, una disconformidad: si el acto jurídico ha nacido a la realidad extrarregistral y no ha acudido al Registro, éste resulta inexacto; cuando el acto acude al Registro entre la vida real y la vida registral existe plena identidad, paralelismo o concordancia. Pues bien, el principio de publicidad inviste de certeza a las declaraciones registrales que se presumen exactas, aun en el supuesto de que dicho contenido registral pueda ser una simple apariencia formal, que no refleja la realidad jurídica del momento; la realidad registral supera a la real en virtud del principio de publicidad y crea una apariencia formal». A este respecto, se han identificado dos corrientes doctrinales, a saber, las monistas ${ }^{17}$ y las dualistas ${ }^{18}$.

El punto de disputa fundamental radica en considerar si la norma está pensando en una única persona o si, por el contrario, se admiten dos posibilidades y en la propia protección que, en consecuencia, se ofrece. Para la tesis monista, solamente podemos encontrarnos un tercero que ha de adquirir el bien de un sujeto que, previamente, tenía inscrito su derecho. Desde esta perspectiva, esta posición (de corte germánica) estaría reafirmando los efectos sustantivos del Registro concretados en la antes mencionada fe pública y la presunción que se genera. Por su parte, la dualista, parte de que esta premisa es predicable del art. $34 \mathrm{LH}$, pero no cabe aplicarla a la persona referida en

15 Por todos, véanse Gordillo Cañas (2004: 95-136); García García (1993a); Jiménez París (2005).

16 En este sentido, véase Faus (2020).

17 Entre otros, algunos de los autores que se han manifestado a favor de esta interpretación, encontramos a Roca Sastre (1965: 781-830); Hermida Linares (1966: 1401-1508); Miquel González (1998: 45-62).

18 En este sentido, a pesar de que difieren en algunos aspectos (como la exigencia de buena fe o que se trate de una transmisión onerosa), véanse Núñez Lagos (1949: 137-171); Lacruz y Sancho (1984); Díez Picazo (2009). 
el art. 32 LH. En este último caso no es necesario, por tanto, que exista un derecho previo inscrito en el Registro por parte del transmitente ${ }^{19}$. Así, este efecto del Registro trae su causa en el principio de inoponibilidad (propio del derecho francés).

Sea como fuere, a pesar de que se ha escrito largo y tendido sobre estas disquisiciones, podemos afirmar que no existe un acuerdo unánime. No puede obviarse que nos estamos refiriendo a supuestos en los que se ha celebrado una doble enajenación de inmuebles, con lo que existen dos intereses potenciales. En dicho escenario, se debe decidir cuál de los dos ha de ser atendido y, por tanto, cuál se tiene que sacrificar. La discrepancia principal entendemos que se produce por la confrontación de dos sistemas: el general, que no exige para los derechos reales inscripción alguna; y el previsto en la Ley Hipotecaria, que parece otorgar un estatus especial al derecho que consta en el Registro frente a otros. Así, nos podemos encontrar con un sujeto al que corresponde el bien de acuerdo con las normas civiles que regulan su transmisión y con otro al que, a pesar de la problemática producida en el negocio del que trae causa, se encuentra protegido por la normativa hipotecaria. Pues bien, a nuestro parecer, la solución óptima pasa por aplicar una teoría intermedia que, acogiendo las ideas de ambas posiciones (monista y dualista), ofrezca una solución más acorde con nuestro ordenamiento.

De la tesis primera, debemos aceptar la idea de que los arts. 32 y $34 \mathrm{LH}$ están aludiendo a una misma realidad, a saber, tutelar la figura del adquirente que actúa de una forma diligente. Por su parte, de la segunda, hemos de seleccionar la premisa de que nos encontramos ante dos sujetos diferentes: uno previsto en el art. $32 \mathrm{LH}$ y, otro, en el art. $34 \mathrm{LH}$. Para el del art. $32 \mathrm{LH}$, no cabe exigir que el título del transmitente se encuentre debidamente inscrito en el Registro, pues de no ser así se estarían atribuyendo nuevas exigencias en el derecho español que no encuentran justificación legal y se estaría admitiendo una suerte de inscripción constitutiva de los derechos. Tal y como destacan algunos autores ${ }^{20}$, la protección se ha de ofrecer al comprador diligente y este

19 No obstante, hay que tener en cuenta que: «Esta asimilación de ambos terceros lleva igualmente a aplicarle al primero de ellos la suspensión de la protección que prevé el artículo 207 Ley Hipotecaria durante el plazo de dos años desde la inmatriculación del derecho mediante título público de adquisición (art. 205 Ley Hipotecaria), o certificado al que se refiere el artículo 206; o la consecuencia del artículo 28 Ley Hipotecaria por el mismo plazo para la inscripción de un derecho adquirido por herencia o legado desde la muerte del causante, salvo que el mismo corresponda a un heredero forzoso». En este sentido, véase Valpuesta Fernández (2005: 1515).

20 A este respecto, señalan Lacruz y Sancho (1984: 167) que «la protección al comprador diligente que inscribe y la que se presta a quien confía en el Registro no contemplan 
se identifica tanto con el que inscribe su derecho como con el que presta confianza al Registro al comprobar su contenido ${ }^{21}$.

No obstante, precisamente porque estamos ante situaciones sustancialmente similares, se deben exigir el resto de los criterios establecidos en el art. $34 \mathrm{LH}$, es decir, se ha de tratar de un negocio a título oneroso y el adquirente ha de actuar de buena fe. Sea como fuere, esta última, por aplicación del principio de fe pública, se presume iuris tantum, de tal suerte que será el interesado el que tendrá que probar el conocimiento de la inexactitud del Registro, en definitiva, la mala fe. Otra solución estaría amparando consecuencias no queridas por nuestro sistema. Además, no se puede perder de vista que se estaría alterando la regla nemo plus iura ad alium transferre potest quam ipse habet, para lo cual se han de exigir ciertas medidas y requisitos.

Asimismo, hemos de añadir una reflexión. A este respecto, consideramos que es relevante el momento de celebración de los negocios jurídicos, no para aplicar la máxima prior tempore, sino para incidir, de nuevo, en la idea de la diligencia. En este sentido, estas disquisiciones se plantean, desde nuestra perspectiva, cuando el primer contrato que se acuerda es el que, $a$ posteriori, no se inscribe (por este motivo, precisamente, se habla de tercero hipotecario). Y ello, porque de ser al contrario, el adquirente (que sería, en estos casos, el «tercero no hipotecario») no habría desplegado los actos que un ciudadano medio hubiera llevado a cabo en su lugar. Entendemos, pues, que el ordenamiento jurídico no puede tratar de favorecer a los particulares que han demostrado no ser aptos para operar en el ámbito jurídico y sería injusto dar preferencia a estos últimos frente a los que sí realizaron estos actos de un modo cuidadoso. Lógicamente, este contexto general es aplicable en unas condiciones normales y de plena capacidad de obrar de las partes.

Somos conscientes de que esta postura puede dar lugar a situaciones de abuso, pero la fórmula prevista en la Ley Hipotecaria no está pensando en estas circunstancias. De esta aproximación no puede extraerse, sin embargo, que tales conductas deban quedar impunes. Nada más lejos de la realidad. Muy al contrario, el ordenamiento jurídico incluye herramientas para hacer frente a las mismas, como, por ejemplo, instar la nulidad del contrato que celebró con

necesariamente supuestos distintos, sino que en los casos más frecuentes se solapan, se superponen».

21 En este caso, parte de la doctrina refiere la apariencia, que aparece como una nueva categoría que se ha de sustentar «un conjunto de soluciones que encajen dogmáticamente, y ello se hace desde la neutralidad jurídica respecto de las situaciones concretas a las que se ha de aplicar». Sobre el particular, véase Valpuesta Fernández (2005: 1559). 
el comprador por tener un objeto o una causa ilícita o porque se ha celebrado con algún vicio ${ }^{22}$, así como la responsabilidad civil correspondiente. Igualmente, tales hechos podrían ser constitutivos de delito. Otra cuestión es que el otro sujeto que adquiere el bien se introduzca, de algún modo, en este fraude a través de una suerte de confabulación. En este contexto, no se puede obviar que no se estaría cumpliendo con el requisito de la buena fe y que, por tanto, no se tutelaría su derecho desde el punto de vista registral. En este último supuesto, quizá, a pesar de que la actitud del «tercero no hipotecario» no es la idónea, podría tener preferencia en el mantenimiento de su derecho real.

Como se puede comprobar, la protección que se ofrece a las personas implicadas (con el derecho inscrito) se produce a través de una intervención ex post. En otras palabras, lo que tutela este principio registral es, precisamente, las situaciones jurídicas consolidadas e inscritas en el Registro. Sea como fuere, no se puede obviar que: «La protección del tercero hipotecario en un sistema de fe pública registral como el nuestro, es una buena solución cuando el conflicto se plantea entre sujetos indiferenciados, pero puede ser cuestionable ante determinados sujetos que gozan de un amparo constitucional ${ }^{23}$. A este respecto, la Constitución española y, en su seno, los derechos fundamentales, así como el resto de la normativa vigente, podrían fundamentar una solución diferente por tratarse de «sujetos diferenciados». Piénsese, por ejemplo, en la condición de consumidor o usuario y el posible tratamiento que merecería. No obstante, no vamos a entrar en mayores disquisiciones por exceder de la finalidad de esta obra.

\section{EL PRINCIPIO DE PUBLICIDAD FORMAL Y LOS DERECHOS FUNDAMENTALES PREVISTOS EN EL ART. $18 \mathrm{CE}$ : LA PROTECCIÓN EX ANTE Y SU REVISIÓN CONSTITUCIONAL}

En otro orden de cosas, hemos de aludir al principio de publicidad formal que, tal y como hemos tenido ocasión de señalar, supone la posibilidad

22 En este sentido, a pesar de que los vicios del consentimiento, generalmente, se encuadren dentro del ámbito de la anulabilidad, entendemos que, en ciertos casos, la consecuencia lógica es la nulidad. Y ello, porque no se puede afirmar que, en determinadas circunstancias, exista una verdadera voluntad, esto es, un consentimiento adecuado. Piénsese, por ejemplo, en aquellos negocios que se celebran con violencia o intimidación, en los que no se permite que la parte afectada forme una decisión propia o en aquellos en los que el error es muy patente.

23 Sobre el particular, véase Valpuesta Fernández (2005: 1560-1574). 
de que terceros con interés ${ }^{24}$ accedan al contenido del Registro. En este caso, a diferencia de lo que ocurre con la publicidad material, la protección que se ofrece es con carácter ex ante, esto es, se permite que se lleve a cabo una actuación previa para asegurar ciertas facultades y, con ello, prevenir, precisamente, que se produzcan problemáticas análogas a las que analizamos al referirnos al mencionado principio (u otras similares). El fundamento es, pues, el mismo que destacamos: salvaguardar la seguridad del tráfico jurídico inmobiliario $y$, en última instancia, el mercado. Sin embargo, entendemos que en este punto pueden producirse interpretaciones erróneas acerca de la aplicación de la perspectiva formal.

A este respecto, el carácter público del Registro y la posibilidad de conocer los datos en él inscritos se han de examinar con cierta cautela. En este sentido, no cabe considerar el referido tráfico jurídico en un sentido amplio, de tal forma que se confunda la finalidad misma del principio. Lo cierto es que desde la perspectiva de los terceros que desean poseer información acerca de la persona, obtendrán mayor beneficio a medida que aumente este extremo. Sin embargo, no debemos poner énfasis en estos sujetos abstractos y que se convierta en una suerte de registro profesional de las actividades inmobiliarias (o de contratación). De ser así, se estaría desnaturalizando el Registro y se estaría creando un fichero al que las personas acudirían para saber las actividades del sujeto con el que pretenden negociar y, por tanto, su forma de actuar. Dicho en otras palabras, no se ha de permitir que se aproxime cualquier persona a dicha información ni, tampoco, que se incluya una cantidad de datos que no se justifique en atención al objetivo.

Muy al contrario, se ha de tutelar la posición de sujetos, más o menos concretos e identificables, que presenten una necesidad digna de amparo. Entre otras situaciones, podemos encontrar aquellos que precisen obtener cuestiones relativas a un bien, por ejemplo, porque van a celebrar un contrato de compraventa con el (supuesto) propietario. De hecho, esta es la conducta que anteriormente reputamos como diligente desde el punto de vista de la ciudadanía. Además, se permitirá que se conozcan los datos estrictamente imprescindibles para satisfacer su interés, sin que quepa, tal y como hemos señalado, ampliar el espectro hasta límites insospechados. Sobre estas cuestiones se ha manifestado la Dirección General de Seguridad Jurídica y Fe Pública ${ }^{25}$

24 Cabe destacar que, como indica el art. $221 \mathrm{LH}$, el citado interés se presume cuando se trate de autoridades, empleados o funcionarios públicos que actúen por razón de su oficio o cargo.

25 Hay que tener en cuenta que la Dirección General de los Registros y del Notariado fue suprimida por el art. 2.2 del Real Decreto 139/2020, de 28 de enero, por el 
en múltiples resoluciones, en las que ha afirmado que «la publicidad ha de ser para finalidades de la institución registral como la investigación, en sentido amplio, patrimonial y económica (crédito, solvencia y responsabilidad), así como la investigación estrictamente jurídica encaminada a la contratación o a la interposición de acciones judiciales ${ }^{26}$. Por tanto, corresponde al registrador decidir qué datos deben ser publicados y las personas a las que se le permite acceder a los mismos ${ }^{27}$.

que se establece la estructura orgánica básica de los departamentos ministeriales. A partir de este momento, tal y como señala el art. 2.1 del mencionado Real Decreto, la misma pasa a denominarse Dirección General de Seguridad Jurídica y Fe Pública, como órgano directivo dependiente de la Secretaría de Estado de Justicia (esta última, como órgano superior del Ministerio de Justicia).

En este sentido, véase la resolución 8598/2017, de 27 de junio (RJ 2017\3774). Asimismo, la resolución 4362/2020, de 9 de enero (RJ 2020\929) destaca que el interés legítimo no se puede apreciar ante una solicitud genérica de información sobre el patrimonio de las personas. Sobre estas cuestiones, véanse, entre otras, las resoluciones 2936/2017, de 1 de marzo (RJ 2017\739); y 245/2017, de 19 de diciembre (RJ 201616632). Igualmente, véase la resolución de la Dirección General de Seguridad Jurídica y Fe Pública, de 3 de junio (RJ 2020\3358).

27 A este respecto, desde una perspectiva expost, podemos afirmar que no se han cumplido las obligaciones impuestas al registrador en este ámbito por varios motivos. De un lado, hemos de observarlo desde el prisma del principio de legalidad que implica que el registrador deberá, con carácter previo, revisar y controlar (en definitiva, calificar) los documentos que se pretender incorporar. Pues bien, tal y como ha declarado el Tribunal Constitucional, a pesar de que la medida es legal (en la medida que se encuentra prevista la posibilidad de llevar a cabo anotaciones derivadas de procedimientos penales), lo cierto es que vulneraba ciertos derechos de la persona afectada. Por este motivo, podría plantearse si el registrador ha incumplido, en cierta forma, sus deberes al inscribir, en los términos descritos, la prohibición de disponer. Sobre el particular, hemos de destacar que la función calificadora del registrador se refiere tanto a la forma como al propio Registro y a la legalidad. Sea como fuere, este extremo sería, al menos, discutible, ya que no se puede obviar que la medida proviene de un auto judicial al cual se atribuye cierta formalidad y diligencia.

De otro lado, el principio de legitimación conlleva que se presume (iuris tantum), salvo prueba en contrario, que los derechos reales que constan en el Registro existen y que pertenecen a su titular en la forma determinada por el asiento respectivo. A este respecto, en realidad, el bien inmueble figuraba a nombre de la mercantil y no del sujeto investigado. Cabe discutir si la investigación llevada a cabo por las autoridades es suficiente para acabar con la citada presunción y para entender que su adquisición se produjo como consecuencia de la realización de actividades delictivas. Más tarde volveremos sobre estas cuestiones. 
Si se observa con detenimiento, las dos dimensiones del principio de publicidad se encuentran, tal y como antes destacamos, íntimamente relacionadas. Así, precisamente la publicidad formal sirve para evitar que un tercero pueda beneficiarse de la publicidad material, en determinados casos. En este sentido, la anotación registral de una limitación del derecho real impedirá que ese tercero que lo adquiere pueda ser considerado de buena fe, en la medida en que tenía conocimiento del gravamen inscrito. Igualmente, hemos visto como existen posiciones doctrinales que entienden que no cabe alegar la publicidad material para tutelar a un sujeto que adquiere la propiedad de un inmueble de una persona que aparentemente actúa como dueño, si no consta como tal en el Registro, pues, sencillamente, no dispondrá de un título válido para proceder. Es, por tanto, desde esta perspectiva desde la cual, entendemos, se ha de producir el análisis del principio de publicidad formal y no en función de otros términos o condiciones.

Así las cosas, podemos encontrar ciertas actividades que sean excesivamente gravosas para el titular del derecho y, en algún caso, injustificadas. Sobre el particular, se pronuncia la antes citada STC 28/2020, de 24 de febrero, en la que el tribunal debe dirimir si una anotación registral derivada de una medida cautelar aprobada en un procedimiento penal supone una injerencia en el derecho al honor del demandante de amparo, en tanto que incluye la especificación de los delitos que, presuntamente, ha cometido este último ${ }^{28}$.

Resulta muy relevante, en este punto, llevar a cabo una distinción que, sin embargo, no aborda directamente el Tribunal Constitucional en la sentencia mencionada. A este respecto, una cuestión es el contenido que debe tener el Registro y, otra distinta, el acceso que las personas pueden tener al mismo. En el primer caso, hemos de acudir a los arts. 9, 72 y $73 \mathrm{LH}$, así como a los arts. 51, 165 y 166 del Decreto de 14 de febrero de 1947 por el que se aprueba el Reglamento Hipotecario. Así, como hemos visto, sería discutible si, en el supuesto analizado, es necesario incluir o no los datos penales del sujeto y si el registrador estaría cumpliendo, en caso afirmativo, con la normativa vigente (véase, en particular, el art. 22.8 LH en materia de protección de datos). En el segundo caso, existen, a nuestro parecer, menos dudas acerca de tal extremo. No se puede obviar que está justificado que, en determinadas situaciones,

28 Conviene tener en cuenta que también se alega la posible afectación de la presunción de inocencia, pero este extremo es descartado por el Tribunal en la medida en que se incluye la referencia a que son "presuntos» delitos. 
se impida el acceso a ciertos tipos de datos ${ }^{29}$. Es el contexto de los asientos previstos en los arts. 83 y 84 Ley 20/2011, de 21 de julio, del Registro Civil, en los que, de algún modo, el legislador ha considerado, ex lege, que existe un interés legítimo en que se tutele la privacidad de esa información. Se debe, en suma, al carácter o la naturaleza de dichos datos que se entienden como «sensibles» ${ }^{30}$.

Precisamente por este motivo, desde nuestra perspectiva, la aproximación que se lleve a cabo en este ámbito ha de venir referida también a otros derechos fundamentales previstos en el art. $18 \mathrm{CE}^{31}$ (a saber, intimidad y protección de datos ${ }^{32}$ ) que podrían verse conculcados por una práctica como

29 De igual modo, algo similar se deduce del art. 222.11 LH que remite al desarrollo reglamentario que autorice la restricción del acceso «a la información relativa a determinadas personas, comerciantes o fincas cuando ello venga impuesto por razón de la protección de la seguridad e integridad de las personas o los bienes».

Sobre el particular, a pesar de que no se desarrollará por exceder de la finalidad de esta obra, podría plantearse si algunas de las previsiones incluidas por la reforma de la Ley Hipotecaria efectuada por la Ley 8/2021, de 2 de junio, por la que se reforma la legislación civil y procesal para el apoyo a las personas con discapacidad en el ejercicio de su capacidad jurídica, pueden o no conculcar el principio de publicidad formal.

31 A este respecto, no se puede obviar que se ofrece una cuádruple protección a estos derechos, a saber, constitucional, penal, civil y administrativa. Esta última adquiere especial relevancia, por ejemplo, en el ámbito de la protección de datos. Desde la perspectiva civil, el art. 9 de la Ley Orgánica 1/1982 recoge tres tipos de tutela (tres acciones): inhibitoria (que se traduce en la exigencia de que cese la intromisión), resarcitoria (la posible indemnización por daño moral) y restitutoria (derecho a apropiarse el lucro obtenido).

32 Repárese en que no hemos incluido el derecho a la propia imagen, al que, en algún caso, se le ha atribuido una suerte de manifestación «moral» o social, ligada a la vida privada y familiar del sujeto. No obstante, desde nuestra perspectiva, este extremo no es adecuado porque se está atribuyendo a este derecho un campo de actuación a la primera que no le corresponde y puede generar confusiones con otros derechos como el honor, la intimidad y la protección de datos. En este sentido, entendemos que el derecho a la propia imagen no tutela frente a aquellas intromisiones que afectan a la vida privada de la persona, pues únicamente la protege frente a la captación o reproducción de su información gráfica, en sí misma considerada. Es cierto que el perjuicio que sufre un particular puede no ser el equivalente. Como resulta lógico, la protección de la imagen está referida a un ámbito privativo, esto es, que ha de mantenerse en el anonimato frente a los demás, pero ello no puede entenderse como un sector de la vida privada y familiar. En estos términos, el Fundamento Jurídico $5^{\circ}$ de la STC 83/2002, de 22 de abril (RTC 2002/83), y el Fundamento Jurídico $4^{\circ}$ de la STC 14/2003, de 28 de enero (RTC 2003\14). 
la descrita. En este sentido, estudiaremos la solución ofrecida por el tribunal y plasmaremos nuestro posicionamiento al respecto. Asimismo, a pesar de que no lo llevemos a cabo por exceder de la finalidad de esta obra, sería interesante examinar el derecho de propiedad ${ }^{33}$, ya que, en las circunstancias en las que se producen los hechos, podríamos estar ante una vulneración del mismo.

Con carácter previo al citado análisis, conviene destacar una cuestión de orden previo que, además, hemos de tener muy presente al enfrentarnos a esta temática. De algún modo, los derechos recogidos en el art. $18 \mathrm{CE}$ se han ido formulando y desarrollando paralelamente (como lo demuestra el hecho de

33 A este respecto, cabe destacar que el que el titular de los bienes no era el demandante de tutela en amparo, sino que existía una mercantil, de la cual este último era socio y administrador solidario. Pues bien, lo cierto es que las personas jurídicas pueden ser titulares de ciertos derechos (como la propiedad) y, por tanto, cabe plantear que se han vulnerado sus facultades. En la medida en que no consta que, en ningún momento, el demandante de amparo haya cuestionado la legitimidad de las medidas adoptadas, debemos entender que, en realidad, la actividad investigada es llevada a cabo tanto por este último como por la sociedad referida. Desde esta perspectiva, se habría aplicado una suerte de doctrina del levantamiento del velo, cuyo origen es eminentemente jurisprudencial. Entre otras, véanse las SSTS 590/1984, de 20 de mayo (RJ 198412800); 1221/2002, de 17 de diciembre (RJ 2002510751); 326/2013, de 16 de mayo (RJ 2013\3701); 667/2017, de 14 de diciembre (RJ 2017\5811); 507/2020, de 14 de octubre (RJ 2020\4095).

En palabras de la actual Dirección General de Seguridad Jurídica y Fe Pública, consiste «en un instrumento jurídico que se pone al servicio de una persona, física o jurídica, para hacer efectiva una legitimación pasiva distinta de la que resulta de la relación, contractual o extracontractual, mantenida con una determinada entidad o sociedad a la que la ley confiere personalidad jurídica propia, convirtiendo a los que serían «terceros» — los socios o la sociedad — en parte responsable a partir de una aplicación, ponderada y restrictiva de la misma, que permita constatar una situación de abuso de la personalidad jurídica societaria perjudicial a los intereses públicos o privados, que causa daño ajeno, burla los derechos de los demás o se utiliza como un medio o instrumento defraudatorio, o con un fin fraudulento y que se produce, entre otros supuestos, cuando se trata de eludir responsabilidades personales, y entre ellas el pago de deudas». En este sentido, véase resolución 7835/2016, de 12 de julio de 2016 (RJ 2016\4262). Igualmente, véanse resolución 14156/2018, de 24 de septiembre (RJ 2018\4311); resolución 11204/2018, de 26 de julio (RJ 2018\3511).

Como señala López Bustabad (2018: 141-158), supone «un remedio o recurso de justicia y equidad, para tratar de evitar las injustas y dañosas consecuencias derivadas de la manipulación de la forma externa de las personas jurídicas y de un ejercicio abusivo de la figura de la persona jurídica». Asimismo, para más información, véase De Ángel Yagüez (1990). 
que sea una única norma la que desarrolle la mayoría de ellos) y ello puede dar lugar a confusiones entre los campos de aplicación de cada uno ${ }^{34}$.

Sin duda, el nexo común de todos es la dignidad, de tal suerte que aluden a una misma realidad y tienen una finalidad compartida: el libre desarrollo de la personalidad. No obstante, cada uno de los derechos se proyecta sobre una dimensión propia, amparando una serie de facultades y estableciendo mecanismos de protección frente a ciertas conductas. Como recuerda el Tribunal Constitucional, los derechos fundamentales previstos en el art. 18 CE tienen sustantividad y contenido propio en nuestro ordenamiento jurídico y ninguno queda subsumido en el otro ${ }^{35}$.

\section{BREVE REFERENCIA A LA CONFIGURACIÓN DE LOS DERECHOS AL HONOR, LA INTIMIDAD Y LA PROTECCIÓN DE DATOS: CONCEPTOS Y CARACTERÍSTICAS ESENCIALES}

\subsection{El derecho al honor}

En primer lugar, al referirnos al derecho al honor, hemos de tratar de partir de un concepto que englobe las características básicas del mismo. No obstante, debemos tener en cuenta que ni en el texto constitucional, en su art. 18.1, ni en la propia Ley Orgánica 1/1982, de 5 de mayo, de protección civil del derecho al honor, a la intimidad personal y familiar y a la propia imagen, se contempla una definición precisa acerca de qué hemos de entender por tal. Por ello, para indagar sobre sobre estas disquisiciones, tenemos que reflexionar sobre su naturaleza jurídica y la interpretación que ha ofrecido el Tribunal Constitucional a este respecto.

Por lo que se refiere a la naturaleza del mismo, podemos destacar que se trata de un derecho de la personalidad ${ }^{36}$, esto es, un derecho subjetivo que aparece como el particular sentimiento que cada persona tiene de su propia dignidad, así como la valoración social que hagan los demás. Se trata, pues, de un concepto relativo referido a la buena reputación de una persona (a ser respetado), de tal forma que se ha de proteger «frente a expresiones o mensajes

34 Sobre las relaciones entre el derecho a la intimidad y la protección de datos personales, Guichot (2005a; 2005b).

35 En este sentido, véanse Fundamento Jurídico $2^{\circ}$ de la STC 81/2001, de 26 de marzo (RTC 2001\81); Fundamento Jurídico 3o de la STC 156/2001, de 2 de julio (RTC 2001\156).

36 Lo cierto es que gran parte de estos derechos de la personalidad no se encontraban reconocidos en los textos originarios del Código Civil, sino que se formaron a lo largo del siglo XX, gracias a la doctrina y la jurisprudencia. En definitiva, se trata de derechos indisponibles, inalienables, imprescriptibles e inembargables. 
que la hagan desmerecer en la consideración ajena al ir en su descrédito o menosprecio ${ }^{37}$. Desde esta perspectiva, este derecho "ampara la buena reputación de una persona, protegiéndola frente a expresiones o mensajes que la hagan desmerecer en la consideración ajena al ir en su descrédito o menosprecio o que sean tenidas en el concepto público por afrentosas ${ }^{38}$.

Además, al tratarse de un derecho de la personalidad, afecta a la propia esfera de las personas, es absoluto e inherente a la dignidad humana ${ }^{39}$. Esta última aparece plasmada en el art. $10 \mathrm{CE}$ y supone el sustratum o prius lógico de todos los derechos fundamentales. Sobre estas cuestiones se manifiesta el Fundamento Jurídico $4^{\circ}$ de la STC 133/2018, de 13 de diciembre ${ }^{40}$ y señala que el honor es un «concepto jurídico normativo cuya precisión depende de las normas, valores e ideas sociales vigentes en cada momento». A este respecto, la primera cuestión sobre la que nos pone sobre aviso el preámbulo de la citada Ley Orgánica 1/1982 es la relativa a la relación existente entre estos derechos y las ideas y pautas socialmente admitidas. Igualmente, su contenido variará en función de los propios actos del sujeto, de tal suerte que su comportamiento repercutirá y servirá para determinar la protección que se ofrece.

En este sentido, entiende el legislador que corresponde al juzgador adaptar la esfera de protección a los tiempos y a las personas concretas. En esta misma línea, posteriormente, el artículo 2 de la citada norma prevé que la protección civil que se dispense al honor, a la intimidad y a la propia imagen quedará delimitada "por las leyes y por los usos sociales atendiendo al ámbito que, por sus propios actos, mantenga cada persona reservado para sí misma o su familia». Por otro lado, tal y como señala el Tribunal Constitucional ${ }^{41}$, la actividad profesional queda amparada en el derecho al honor,

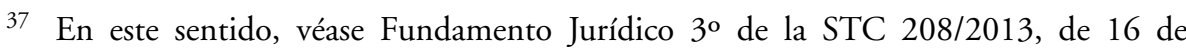
diciembre (RTC 2013\208).

38 En este sentido, véase Fundamento Jurídico 12o de la STC 14/2003, de 28 de enero (RTC 2003\14). Asimismo, en esta misma línea, véanse Fundamento Jurídico $6^{\circ}$ de la STC 127/2003, de 30 de junio (RTC 2003\127); Fundamento Jurídico 7o de la STC 216/2006, de 3 de julio (RTC 2006\216); y Fundamento Jurídico $3^{\circ}$ de la STC 51/2008, de 14 de abril (RTC 2008151).

39 A este respecto, véanse, entre otras, las SSTC 231/1988, de 2 de diciembre (RTC 1988\231); 170/1994, de 7 de junio (RTC 1994\170); 176/1995, de 11 de diciembre (RTC 1995\176); 51/2008, de 14 de abril (RTC 2008\51); 23/2010, de 27 de abril (RTC 2010\23).

40 RTC 2018\133.

41 En este sentido, véanse Fundamento Jurídico 5o de la STC 180/1999, de 11 de octubre (RTC 1999\180); Fundamento Jurídico 5º de la STC 41/2011, de 11 de abril (RTC 2011\41). 
en la medida en que suele ser una de las formas más destacadas de manifestación externa de la personalidad y de la relación del individuo con el resto de la colectividad. De esta suerte, «la descalificación injuriosa o innecesaria de ese comportamiento tiene un especial e intenso efecto sobre dicha relación y sobre lo que los demás puedan pensar de esa persona, repercutiendo tanto en los resultados patrimoniales de su actividad como en la imagen personal que de ella se tenga».

Por todo ello, como regla general, debemos entender que serán consideradas como intromisiones ilegítimas todas aquellas que se lleven a cabo sin contar con la previa autorización del sujeto ${ }^{42}$, salvo que una ley expresamente lo autorice. Además, este consentimiento será revocable en cualquier momento indemnizando, en su caso, los daños y perjuicios causados (art. 2.3 Ley Orgánica 1/1982). En este sentido, los apdos. 3, 6, 7 y 8 del art. 7 de la precitada ley recogen una serie de actuaciones que son consideradas, ex lege, como intromisiones ilegítimas. No obstante, no puede considerarse un derecho absoluto, ya que admite ciertas excepciones. Máxime cuando nos

42 Además, no se puede obviar que ha de ser un consentimiento informado, es decir, que debe venir precedido de una adecuada información acerca de los fines y el destino para los que va a ser empleada la imagen y los medios en los que, en su caso, va a ser publicada, entre otras cuestiones. En cuanto a la forma en que tiene que llevarse a cabo, sin entrar en mayor abundamiento, baste con señalar que, a pesar de que la Ley mencionada exige que sea expreso, la jurisprudencia ha relajado este criterio. A este respecto, en algunos pronunciamientos se ha venido manteniendo que el precitado precepto ha de interpretarse en el sentido de que la autorización puede prestarse de forma tácita y deducirse «de actos o conductas de inequívoca significación, no ambiguas o dudosas». Asimismo, hemos de añadir tres reflexiones sobre el particular. En este sentido, véanse, entre otras, las SSTS 1116/2002, de 25 de noviembre (RJ 2002\10274); 131/2006, de 22 de febrero (RJ 2006\830).

Asimismo, con carácter general, debemos indicar que este consentimiento supone un ejercicio del derecho o, al menos, ese debe ser el espíritu de la norma. En este sentido, que se trate de un derecho irrenunciable e inalienable no conlleva que, lógicamente, se reconozcan ciertas facultades al titular para que el propio gozo y disfrute se desarrolle adecuadamente. En suma, como muy acertadamente apunta De Verda y Beamonte (2014: 35), es una «expresión de un acto de autonomía de la persona», que, en ningún caso "puede ser considerado como fuente de una obligación contractual (aunque sea dado, mediando el pago de una suma de dinero), ni tampoco supone, en sentido estricto, un acto de disposición». Muy al contrario, la autorización «opera como una causa de exclusión de la ilegitimidad de una intromisión, que, de no darse dicho consentimiento, sería antijurídica (con las pertinentes consecuencias, como son, en el orden civil, la reparación del daño moral ocasionado). Los bienes de la personalidad, no pueden ser objeto de tráfico jurídico». 
encontramos ante una supuesta colisión con otros derechos fundamentales, como la libertad de expresión e información previstas en el art. 20 letras a) y d), respectivamente ${ }^{43}$.

Muy resumidamente, podemos señalar que para que pueda considerarse justificada una intromisión en el derecho al honor es preciso que la información o la expresión se refiera a "asuntos de relevancia pública o interés general, ya por la propia materia a la que aluda la noticia o el juicio de valor, ya por razón de las personas, esto es, porque se proyecte sobre las que ejerzan un cargo público o una profesión de notoriedad o proyección pública» ${ }^{44}$.

\subsection{El derecho a la intimidad}

En este caso, de nuevo nos encontramos ante un derecho de la personalidad, por lo que son aplicables, mutatis mutandi, las mismas reflexiones que realizamos al respecto. Sea como fuere, este derecho tutela un ámbito diferente y que debemos tratar de concretar. En este sentido, la intimidad alude a la esfera más íntima y secreta que toda persona tiene derecho a reservarse para sí y su familia ${ }^{45}$. No obstante, esta vida privada no puede restringirse en exceso "a un "círculo íntimo» en el que el individuo puede conducir su vida personal a su manera y excluir plenamente el mundo exterior no incluido en este círculo. No puede desconocerse que también en otros ámbitos, y en particular en el relacionado con el trabajo o la profesión, se desarrollan relaciones interpersonales, vínculos o actuaciones que pueden constituir manifestación

43 A este respecto, los criterios que se han de manejar son dos, a saber, que los hechos tengan interés público y sean veraces (contrastados con la debida diligencia). En el caso de la libertad de expresión no exige un deber de veracidad, pero sí que los pensamientos, ideas o juicios que se emitan tengan interés general y que no se limiten a ser meramente vejatorias. Asimismo, el artículo 8.1 de la Ley Orgánica 1/1982 señala que no se reputarán intromisiones ilegítimas aquellas que hayan sido «autorizadas o acordadas por la Autoridad competente de acuerdo con la ley, ni cuando predomine un interés histórico, científico o cultural relevante».

44 En este sentido, véase Sempere Navarro (2020: 5).

45 Así, el Tribunal Constitucional ha tenido ocasión de señalar que el derecho a la inti midad atribuye a su titular una suerte de poder de resguardar ese ámbito reservado por el individuo para sí y su familia de una publicidad no querida, esto es, de imponer a terceros el deber de abstenerse de toda intromisión en la esfera íntima y la prohibición de hacer uso de lo así conocido. En este sentido, véanse, entre otras, las SSTC 196/2004, de 15 de noviembre (RTC 2004\196); 206/2007, de 24 de septiembre (RTC 2007\206); 236/2007, de 7 de noviembre (RTC 2007\236); 70/2009, de 23 de marzo (RTC 2009\70); 60/2010, de 7 de octubre (RTC 2010\60). 
de la vida privada $»^{46}$. Para delimitar estas cuestiones, el Tribunal Constitucional alude al criterio de las "expectativas razonables» ${ }^{47}$, que se concreta en la esperanza que el titular (o cualquier otra persona en su lugar o, si se quiere, un espectador objetivo) podría tener de encontrarse ajeno a la observación de terceros.

En suma, se trata de mantener un «ámbito propio y reservado frente a la acción y conocimiento de los demás» ${ }^{48}$, esto es, frente a la acción y conocimiento de terceros. En otras palabras, es «el poder de resguardar ese ámbito reservado por el individuo para sí y su familia de una publicidad no querida ${ }^{49}$ y, en consecuencia, «el poder jurídico de imponer a terceros el deber de abstenerse de toda intromisión en la esfera íntima y la prohibición de hacer uso de lo así conocido" ${ }^{50}$. En todo caso, tampoco en este supuesto nos encontramos ante un derecho absoluto, recogiendo el art. 7 (apdos. 1, 2 y 4) de la Ley Orgánica 1/1982 las intromisiones consideradas ilegítimas. Al margen de este extremo, de nuevo, el consentimiento de la persona elimina tal carácter. Igualmente, en las relaciones de este derecho con el derecho a la información

46 A este respecto, véase Fundamento Jurídico 5 de la STC 12/2012, de 30 de enero (RTC 2012\12).

47 Sobre el particular, la precitada STC 12/2012, de 30 de enero, nos recuerda que las expectativas razonables vienen referidas a las que tendría la persona o cualquier otra en su lugar en esa circunstancia, «de encontrarse al resguardo de la observación o del escrutinio ajeno. Así por ejemplo cuando se encuentra en un paraje inaccesible o en un lugar solitario debido a la hora del día, puede conducirse con plena espontaneidad en la confianza fundada de la ausencia de observadores. Por el contrario, no pueden abrigarse expectativas razonables al respecto cuando de forma intencional, o al menos de forma consciente, se participa en actividades que por las circunstancias que las rodean, claramente pueden ser objeto de registro o de información pública». También el Tribunal Europeo de Derechos Humanos se ha manifestado sobre estas cuestiones. Para más información, véanse SSTEDH de 25 de septiembre de 2001, caso $P$. G. y J. H. c. Reino Unido (TEDH 2001\552); y de 28 de enero de 2003, caso Peck c. Reino Unido (JUR 2003, 50030).

48 En este sentido se manifiesta el Fundamento Jurídico 2o de la STC 77/2009, de 23 de marzo (RTC 2009177).

49 A este respecto, véanse Fundamento Jurídico $3^{\circ}$ de la STC 231/1988, de 2 diciembre (RTC 1988\231); Fundamento Jurídico $11^{\circ}$ de la STC 236/2007, de 7 de noviembre (RTC 2007\236); Fundamento Jurídico $8^{\circ}$ de la STC 60/2010, de 7 de octubre (RTC 2010\60).

50 Véanse Fundamento Jurídico 2o de la STC 196/2004, de 15 de noviembre (RTC 2004\196); Fundamento Jurídico 5 de la STC 206/2007, de 24 de septiembre (RTC 2007\206); Fundamento Jurídico 2º de la STC 70/2009, de 23 de marzo (RTC 2009\70). 
han de tenerse en cuenta las mismas consideraciones que destacamos, de tal forma que el primero "puede ceder ante la prevalencia de otros derechos, como el derecho a la información cuando se refiera a hechos con relevancia pública, en el sentido de noticiables, y a que dicha información sea veraz» ${ }^{51}$.

Por lo que respecta a los hechos noticiables, indica el Tribunal Constitucional que han de entenderse aquellos que versen sobre materias de relevancia pública que sean de interés general (ya por la propia temática, ya por las personas que intervengan) y que contribuyan a la formación de la opinión pública $^{52}$. Por su parte, la veracidad hay que relacionarla con que hayan sido contrastados con la debida diligencia profesional y, además, este deber «no se satisface con la pura remisión a fuentes indeterminadas que, en ningún caso, liberan al autor de la información del cumplimiento de dicho deber, pues al asumir y transmitir a la opinión pública la noticia, también asume la veracidad o inveracidad, en cuanto que la obligación de contrastar la verosimilitud de la noticia es un deber propio y específico de cada informador $\aleph^{53}$.

\subsection{El derecho a la protección de datos}

En otro orden de cosas, hemos de referirnos a la protección que reciben los datos personales en nuestro ordenamiento jurídico. Inicialmente, puede pensarse que estamos ante un mero derecho de carácter legal que, a pesar de su relevancia, no adquiere implicaciones constitucionales. De hecho, si bien el art. 18.4 CE se refiere a la necesaria limitación del uso de la informática, lo cierto es que la Ley Orgánica 1/1982 desarrolla los derechos fundamentales del anterior precepto y no hace alusión a los datos personales. No obstante, esta conclusión no concuerda con el carácter de la casi derogada Ley Orgánica 15/1999, de 13 de diciembre, de Protección de Datos de Carácter Personal. A este respecto, a pesar que no se incluyó, en ningún punto, que se trataba de un derecho fundamental, el legislador entendió que debía ser una norma con rango de ley orgánica la encargada de regular estas cuestiones.

Sobre estas disquisiciones, se ha ocupado el Tribunal Constitucional que, en algunos pronunciamientos, ha puesto de relieve que el artículo 18.4 CE incorpora «un instituto de garantía de otros derechos, fundamentalmente [pero

51 Véase Fundamento Jurídico 20 de la STC 77/2009, de 23 de marzo (RTC 2009177).

52 En unos términos similares se manifiesta el Fundamento Jurídico $3^{\circ}$ de la reciente STC 6/2020, de 27 de enero (RTC 202016). Igualmente, véanse los Fundamentos Jurídicos $4^{\circ}$ y $5^{\circ}$ de la STC 18/2015, de 16 de febrero (RTC 2015\18).

53 En este sentido, véase Fundamento Jurídico $3^{\circ}$ de la STC 172/1990, de 12 de diciembre (RTC 1990\172). 
no únicamente] el honor y la intimidad ${ }^{54}$. No obstante, en otras posteriores no se ha limitado a afirmar este extremo, sino que lo ha categorizado como un derecho fundamental contemplado en el art. 18.4 CE. En este sentido, prevé el Tribunal que «el derecho del art. 18.1 de la Constitución queda reformulado si a él se añade la garantía del apartado 4, puesto que la privacidad excede del marco de la intimidad y abarca el control sobre los datos que se refieren a la propia persona " ${ }^{55}$. Así, el art. 18.4 CE alude a un concepto más amplio, el de privacidad, que "excede del marco de la intimidad y abarca el control sobre los datos que se refieren a la propia persona». Además, este precepto estaría reconociendo un derecho fundamental, a saber, el denominado «derecho a la libertad informática» - $\mathrm{O}$ "autodeterminación informativa» ${ }^{56}$ - Este último representa el derecho «a controlar el uso de los mismos datos insertos en un programa informático (habeas data) y comprende, entre otros aspectos, la oposición del ciudadano a que determinados datos personales sean utilizados para fines distintos de aquel legítimo que justificó su obtención» ${ }^{57}$.

El ámbito de aplicación de la privacidad ${ }^{58}$ es más extenso que el de los derechos fundamentales al honor, la intimidad y la propia imagen, de tal suerte

54 En este sentido, véase el Fundamento Jurídico 60 de la STC 254/1993, de 20 de julio (RTC 1993\254), que refiere la libertad informática como derecho a controlar los datos personales.

55 Fundamento de Derecho $3^{\text {o }}$ de la STSJ de Cataluña 5361/2006 (Sección 1a), de 12 de julio (AS 2007\1027).

56 En este sentido, véase Fundamento Jurídico 2o de la STC 292/2000, de 30 de noviembre (RTC 2000\292). Este pronunciamiento declaró contrarios y, por tanto, nulos varios incisos de los arts. 21.1 y 24.1, así como varios incisos del apdo. primero y del apdo. 2 del citado art. 24 de la Ley Orgánica 15/1999, de 13 de diciembre, de Protección de Datos de Carácter Personal (derogada desde el 7 de diciembre de 2018 a salvo de lo previsto en las disposiciones adicional 14 y transitoria 4 de la Ley Orgánica 3/2018).

57 Véase Fundamento Jurídico 4o de la STC 94/1998, de 4 de mayo (RTC 1998\94).

58 Sobre el particular, interesa poner de relieve que el desarrollo de este derecho a la privacidad se ha producido en otros países del entorno. Ello ha ocurrido de un modo especialmente patente en el derecho norteamericano, donde la privacy pasó a ocupar un papel esencial en relación con el informed consent sanitario. En este sentido, a partir de la década de los setenta no solo se reconoció el consentimiento informado, sino que el mismo se vinculó al derecho fundamental a la privacy. En sus orígenes, este derecho adquirió una connotación más acotada y referida al rechazo de toda intromisión no consentida en la vida privada. Sin embargo, la cultura jurídica norteamericana, por los distintos factores influyentes, ha ido aplicando esta teoría a distintos ámbitos constitucionalmente protegidos —entre los que se encuentra el sector de la salud—. Para más información sobre este derecho, véase Warren y Brandeis (1980: 184-220). 
que la primera engloba facetas de la personalidad que, aisladamente consideradas, pueden carecer de significación intrínseca pero que, «coherentemente enlazadas entre sí, arrojan como precipitado un retrato de la personalidad del individuo que éste tiene derecho a mantener reservado" ${ }^{59}$. Por todo ello, el citado precepto incluye una manifestación del derecho de autodeterminación, ligado a la privacidad, que tiene una doble vertiente: de un lado, supone un instrumento para garantizar otros derechos y, de otro, es derecho fundamental autónomo.

Por su parte, la normativa vigente ha reforzado este posicionamiento e indica que estamos ante un verdadero derecho fundamental ${ }^{60}$. Así, señala el preámbulo de la Ley Orgánica 3/2018, de 5 de diciembre, de Protección de Datos Personales y garantía de los derechos digitales que estamos ante un derecho fundamental protegido por el art. 18.4 CE. En esta línea se manifiesta parte de la doctrina al señalar que existe un derecho fundamental a la protección de datos personales ${ }^{61}$.

A nuestro parecer, la tesis referida la privacidad como garantía de los derechos fundamentales nos parece adecuada, en la medida en que existirán supuestos en los que la vulneración de la primera derivará en la conculcación de los segundos y otros en los que, al contrario, únicamente se producirá una afectación de la citada privacidad. Así, este extremo permite actualizar y adaptar la Constitución a las realidades y exigencias actuales y que varían muy frecuentemente por el avance de las nuevas tecnologías. Esta conclusión, no obstante, no es extensible a la posibilidad de incluir, de facto, un nuevo derecho fundamental interpretando, quizás, demasiado extensivamente el

59 En tales términos se manifestaba la exposición de motivos de la derogada Ley Orgánica 5/1992, de 29 de octubre, de regulación del tratamiento automatizado de los datos de carácter personal, si bien esta última se refería, únicamente, a la intimidad. A este respecto, destaca la precitada disposición que, si bien «la intimidad, en sentido estricto, está suficientemente protegida por las previsiones de los tres primeros párrafos del artículo 18 de la Constitución y por las leyes que los desarrollan, la privacidad puede resultar menoscabada por la utilización de las tecnologías informáticas de tan reciente desarrollo». No obstante, tal y como hemos destacado anteriormente, entendemos que estos extremos son igualmente predicables tanto del derecho a la información como del derecho al honor.

60 Asimismo, este extremo podría deducirse de otras normas europeas anteriores como el art. 8 de la Carta de los Derechos Fundamentales de la Unión Europea y el art. 16.1 del Tratado de Funcionamiento de la Unión Europea, así como el propio Reglamento (UE) 2016/67.

61 En este sentido, véanse Martínez Martínez (2007: 47-51); Canales Gil (2007: 13-56); Rams Ramos (2018: 119-152). 
art. 18.4 CE. Muy al contrario, consideramos que el mencionado «derecho a la libertad informática» ha de tener carácter y rango legal cuyo origen se fundamenta en el desarrollo de la jurisprudencia y la doctrina constitucional.

Ello no es óbice para que, como hemos destacado, se encuentre vinculado a ciertos derechos fundamentales y que, por tanto, adquiera una importancia y significación relevante. Desde esta perspectiva, es posible que una conculcación de este derecho produzca, a su vez, una afectación de dichos derechos fundamentales, pero no pueden confundirse. A este respecto, no parece que la vía constitucional quede expedita en cualquier caso, sino únicamente cuando los tribunales ordinarios obvien su existencia sin motivar su decisión de acuerdo con los parámetros legales. No quiere decir que se excluya del ámbito de la constitucionalidad y que deba quedar recluido en la legalidad ordinaria interpretada secundum constitutionem, sino que se debe modular el acceso al recurso de amparo en función del caso concreto.

Una vez concretada la naturaleza jurídica de este derecho, debemos tratar de ofrecer un concepto sobre el mismo. A este respecto, si seguimos la definición ofrecida por el art. 4.1 del Reglamento (UE) 2016/679, del Parlamento Europeo y del Consejo, de 27 de abril de 2016, relativo a la protección de las personas físicas en lo que respecta al tratamiento de datos personales y a la libre circulación de estos datos y por el que se deroga la Directiva 95/46/ CE (Reglamento general de protección de datos), por dato personal hemos de entender «toda información sobre una persona física identificada o identificable». Además, este mismo precepto, in fine, recoge, entre los identificadores, los elementos de la identidad física, fisiológica, genética, económica, cultural o social de dicho sujeto.

No obstante, por la incidencia en el objeto de estudio, debemos destacar que los datos personales en los procesos judiciales penales no están sometidos al citado Reglamento (UE) 2016/679 ni a la Ley Orgánica 3/2018, ya que, expresamente, se encuentran excluidos de su ámbito de aplicación (véanse el art. 2.2 del primero y la disposición transitoria $4^{\circ}$ de la segunda). En este campo, pues, tenemos que hacer alusión a la Directiva (UE) 2016/680, del Parlamento Europeo y del Consejo, de 27 de abril de 2016 relativa a la protección de las personas físicas en lo que respecta al tratamiento de datos personales por parte de las autoridades competentes para fines de prevención, investigación, detección o enjuiciamiento de infracciones penales o de ejecución de sanciones penales, y a la libre circulación de dichos datos y por la que se deroga la Decisión Marco 2008/977/JAI del Consejo.

Como esta directiva no ha sido transpuesta al ordenamiento español, la precitada disposición transitoria $4^{\circ}$ de la Ley Orgánica 3/2018 remite a lo 
dispuesto en la Ley Orgánica 15/199962, «en tanto no entre en vigor la norma que trasponga al Derecho español lo dispuesto en la citada directiva». Sin embargo, el legislador español ha incumplido el plazo previsto para proceder en este sentido (finalizó el día 6 de mayo de 2018), por lo que no puede concluirse que los mandatos de la directiva no tengan vigencia en nuestro país. Muy al contrario, la legislación nacional ha de ser interpretada conforme a las exigencias de la misma y, en última instancia, esta adquirirá efecto directo.

Sobre el particular, cabe señalar que el art. 4.1 letras a), b) y c) de la directiva ${ }^{63}$ obliga a que los datos personales sean tratados de forma lícita y leal; que sean recogidos con fines determinados, explícitos y legítimos, y no ser tratados de forma incompatible con esos fines; y que sean adecuados, pertinentes y no excesivos en relación con los fines para los que son tratados.

\section{LA COLISIÓN ENTRE DERECHOS Y EL PRINCIPIO DE PROPORCIONALIDAD FRENTE A LA ADECUADA DELIMITACIÓN DE SUS CONTORNOS}

\subsection{La solución adoptada en la STC 28/2020, de 24 de febrero}

Desde esta perspectiva, el Tribunal Constitucional se enfrenta al supuesto planteado en la STC 28/2020, de 24 de febrero. Para ofrecer una solución

62 En este sentido, el art. 7 de la citada norma, referido a los datos especialmente protegidos, indica en su apartado quinto que: «Los datos de carácter personal relativos a la comisión de infracciones penales o administrativas sólo podrán ser incluidos en ficheros de las Administraciones públicas competentes en los supuestos previstos en las respectivas normas reguladoras». Por su parte, el art. 22 se centra en los ficheros de las Fuerzas y Cuerpos de Seguridad. Por último, hemos de hacer referencia al art. 24 que recoge ciertas excepciones en este ámbito, a saber, no será aplicable a la recogida de datos cuando la información al afectado cuando afecte a la Defensa Nacional, a la seguridad pública o a la persecución de infracciones penales. A este respecto, hemos de señalar que, como tuvimos ocasión de señalar, tanto ciertos incisos del apartado primero como el apartado segundo del citado precepto fueron declarados inconstitucionales por la antes mencionada STC 292/2000, de 30 de noviembre.

63 Asimismo, el apdo. segundo del precepto mencionado señala que se permitirá «el tratamiento de los datos personales, por el mismo responsable o por otro, para fines establecidos en el artículo 1, apartado 1, distintos de aquel para el que se recojan en la medida en que: a) el responsable del tratamiento esté autorizado a tratar dichos datos personales para dicho fin de conformidad con el Derecho de la Unión o del Estado miembro, y b) el tratamiento sea necesario y proporcionado para ese otro fin de conformidad con el Derecho de la Unión o del Estado miembro». 
recurre, tal y como realiza en otros casos en los que se debe dirimir acerca de una posible conculcación de un derecho fundamental, a la idoneidad, necesidad y proporcionalidad de la medida. Así, no se puede obviar que no existen derechos absolutos y que, por tanto, cabe aplicar límites y excepciones a los mismos. No obstante, para que se encuentre justificada la injerencia han de cumplirse tres requisitos: que se prevea en una norma de rango legal, que se oriente a la realización de un fin constitucionalmente legítimo y que se persiga de forma necesaria y proporcional. Sobre las dos primeras cuestiones, ya tuvimos ocasión de señalar que la interpretación acerca de la posibilidad de adoptar medidas cautelares de este tipo en el marco de un procedimiento penal es adecuada y así lo estima la sentencia. En este sentido, el Tribunal entiende que el contenido del auto y, por tanto, la finalidad perseguida con la medida cautelar, están justificadas y son correctas.

Por otro lado, para responder al tercer requisito, se recurre al juicio de proporcionalidad $^{64}$ que se compone, a su vez, de tres juicios: que la medida sea susceptible de conseguir el objetivo propuesto (juicio de idoneidad); que, además, sea necesaria, en el sentido de que no exista otra medida más moderada para la consecución de tal propósito con igual eficacia (juicio de necesidad); y, finalmente, que la misma sea ponderada o equilibrada, por derivarse de ella más beneficios o ventajas para el interés general que perjuicios sobre otros bienes o valores en conflicto (juicio de proporcionalidad en sentido estricto).

De este modo, el tribunal divide el análisis entre dos hechos. De un lado, la decisión judicial de proceder en el sentido descrito, esto es, de limitar la posibilidad de disponer de los bienes (al ser considerado como un efecto del delito), que ya hemos señalado que es acorde con la normativa vigente. De otro lado, el contenido de la anotación registral, sobre la cual no puede concluirse en igual sentido. En otras palabras, si se quiere, podemos destacar que no se debate el fondo del asunto, esto es, la prohibición de disponer de los inmuebles (como tampoco lo realiza el demandante de amparo), sino la forma en la que se lleva a cabo, es decir, la información que se ha de incluir en el Registro para cumplir con el objetivo que se pretende.

Como tuvimos ocasión de indicar, los apdos. 5 y 6 del art. 727 LEC, aluden a que la publicidad registral sea útil para el buen fin de la ejecución y, a este respecto, no se puede negar que la mera anotación registral de la citada

64 Sobre el particular, véanse Fundamento Jurídico 9o de la STC 14/2003, de 28 de enero (RTC 2003\14); Fundamento Jurídico 2o de la STC 43/2014, de 27 de marzo (RTC 2014\43); Fundamento Jurídico 5º de la STC 170/2013, de 7 de octubre (RTC 2013\170); y Fundamento Jurídico 5º de la STC 39/2016, de 3 de marzo (RTC 2016139). 
prohibición, sin más detalle, bien serviría para alcanzar la finalidad que se busca obtener, a saber, asegurar la efectividad de la posterior sentencia y evitar que los bienes circulen en el mercado sin posibilidad de recuperación. En este sentido, de no ser así, en aplicación del art. $34 \mathrm{LH}$, los futuros adquirentes podrían tener la condición de terceros de buena fe y, por ello, no podría perturbarse su propiedad. Por todo lo anterior, señala la sentencia que se trata de una medida innecesaria y que ha vulnerado el derecho al honor del recurrente.

\subsection{Revisión de la STC 28/2020, de 24 de febrero: otros derechos implicados y criterio de la delimitación de derechos}

Tras ello, conviene que analicemos la solución propuesta por el Tribunal Constitucional. Sobre el particular, podemos realizar, al menos, dos reflexiones. En primer lugar, cabe destacar que la vida en sociedad ha provocado que se produzcan situaciones conflictivas en las que, con cierta frecuencia, se alude a la colisión entre derechos. En este sentido, se ha establecido que, en tales circunstancias, se debe dirimir acerca de la preponderancia y prevalencia de uno de estos derechos y en el sacrificio, por tanto y en consecuencia, del otro. En suma, se trata de determinar entre dos intereses que, en principio, son dignos de protección, cuál ha de ser atendido en el caso concreto. De hecho, existen derechos fundamentales entre los que tales premisas son predicables de un modo más evidente, como ocurre con los derechos del art. $18 \mathrm{CE}$ y las libertades de expresión e información del art. 20.1 letras a) y d) CE).

No obstante lo anterior, desde nuestra perspectiva, esta posición no es adecuada, pues entendemos que los derechos no se formulan desde esta postura conflictiva. Muy al contrario, consideramos que no es necesario acudir a estos razonamientos para dirimir la aplicación de un derecho u otro, ya que, en realidad, los problemas planteados se resuelven con una correcta definición y delimitación de cada uno de ellos. Como pone de relieve parte de la doctrina, la fuerza expansiva de los derechos fundamentales, debido a la abstracción y generalidad de los preceptos constitucionales, conlleva, al menos, dos riesgos. De un lado, "que al determinar el contenido protegido por cada uno de los derechos, el intérprete pretenda introducir en él todo tipo de pretensión, lo que desde luego no solo no es admisible, sino, incluso, puede generar que los derechos fundamentales se devalúen» $y$, de otro lado, "puede suceder que el intérprete caiga en la tentación de ser él quien defina los contenidos de los derechos sin otro criterio que su propia discrecionalidad $»^{65}$.

65 En este sentido, véase Carpio Marcos (2003: 490). 
Por todo ello, a pesar de que el resultado final pueda ser el mismo (esto es, que se ha vulnerado el derecho al honor), a nuestro parecer, la interpretación que se ha de ofrecer ha de atender a la Constitución ( $\mathrm{y}$ al ordenamiento, en general) en conjunto y tratar de atribuir campos de actuación a cada una de las facultades de tal suerte que no existan las pretendidas disputas. En este sentido, muchos de los supuestos que se plantean se deben a un incorrecto entendimiento de los derechos y a una errónea atribución de facultades que no se encuentran amparadas en los mismos ${ }^{66}$. En suma, se intentan tutelar situaciones con base en derechos que, en realidad, no protegen tales contextos.

En esta línea, coincidimos con algunas voces ${ }^{67}$ cuando apuntan que con el ejercicio de los derechos fundamentales nos podemos encontrar ante ciertos «desajustes» y la solución pasa por ese "ajustamiento» entre los condicionantes propios del contexto en el que se ejercen los derechos fundamentales y la exigencia de que sean respetados. En aquellas situaciones más problemáticas no nos encontramos, pues, ante conflictos de derechos o ante restricciones, sino, en su caso, ante una imposibilidad fáctica.

En segundo lugar, a pesar de que no han sido planteados por el recurrente y que, en consecuencia, no se ha manifestado al respecto el Tribunal Constitucional, entendemos que esta medida podría vulnerar otros derechos fundamentales. En este sentido, podría alegarse el derecho a la intimidad en la medida en que se han hecho públicos extremos que atañen a la esfera del investigado. No obstante, este extremo sería, cuanto menos, discutible, ya que no queda claro que pertenezca a su vida privada y familiar. Además, tal y como ha afirmado este Tribunal en otros pronunciamientos ${ }^{68}$ en los que se producían conflictos con los derechos a la comunicación, no existe ninguna duda «en orden a la conveniencia de que la comunidad sea informada sobre sucesos de relevancia penal, y ello con independencia de la condición de sujeto privado de la persona o personas afectadas por la noticia». A este respecto, a pesar de que no se trate de un supuesto totalmente similar, bien pueden extrapolarse

66 Así, por ejemplo, cuando nos referimos al tercero hipotecario, no puede concluirse que los derechos de este último se ponderen de forma superior a los del primer adquirente, sino que, en realidad, este último no posee un derecho real sobre el bien inmueble o un derecho frente al primero. Muy al contrario, dispondrá de acciones contra el vendedor de dicho bien por haber actuado de mala fe.

67 En este sentido, véase De Domingo Pérez (2011: 5-30).

68 Véase Fundamento Jurídico $4^{\circ}$ de la STC 185/2002, de 14 de octubre (RTC 2002\185). En igual sentido se manifiestan el Fundamento Jurídico $4^{\mathrm{o}}$ de la STC 178/1993, de 31 de mayo (RTC 1993\178); el Fundamento Jurídico 5º de la STC 320/1994, de 28 de noviembre (RTC 1994\320); y el Fundamento Jurídico $4^{\circ}$ de la STC 154/1999, de 14 de septiembre (RTC 1999\154). 
estas conclusiones a este supuesto, máxime cuando, en cierta medida, ha sido el investigado el que se ha colocado, voluntariamente, en dicha situación.

Por otro lado, hemos de analizar si se ha conculcado la protección de datos personales. En este punto, la discusión central radica en el concepto de dato personal, esto es, si podemos considerar que la información relativa a los presuntos delitos cometidos puede ser considerada como tal. Desde nuestra perspectiva, a pesar de que, por sí misma, no permite identificar a la persona de que se trata, lo cierto es que las peculiares circunstancias en las que se produce permitían llevar a cabo lo anterior sin excesiva dificultad. Así, no se puede obviar que la condición de socio y administrador de la mercantil del sujeto ofrecía suficientes criterios para que los terceros pudieran llegar a tal deducción. Además, como señalamos anteriormente, este sector viene referido a la privacidad, término más amplio que la intimidad, de tal suerte que podrían encuadrarse perfectamente este tipo de datos.

Sobre estas cuestiones, encontramos múltiples resoluciones de la Dirección General de Seguridad Jurídica y Fe Pública ${ }^{69}$ que han afirmado la necesidad de que se restrinjan tanto las personas que han de ser consideradas como interesadas como la cantidad de datos que se han de incluir en el Registro. Por todo lo anterior, consideramos que el Registrador ha de observar todas estas exigencias y asegurar que se está cumpliendo con la normativa de protección de datos de carácter personal. Además, en el ámbito que nos movemos, son especialmente relevantes las prescripciones que anteriormente señalamos en relación con la Directiva (UE) 2016/680. Así, no se estarían respetando las obligaciones de adecuación, pertinencia y proporcionalidad que se incorporan en el art. 4 de la citada norma. En este sentido, es factible apreciar una conculcación de la protección de datos del recurrente por todos los motivos expresados.

Como se puede comprobar de lo que hemos analizado, los derechos fundamentales aparecen como una suerte de límite directo para los principios registrales, no porque exista un conflicto y, por tanto, una ponderación entre derechos, sino porque ciertas anotaciones pueden no estar justificadas (desde el punto de vista de la función del Registro). No se puede obviar que «los derechos fundamentales operan, en el contexto de los Derechos de los Estados democráticos, como criterios para identificar el Derecho válido y son, en cierto modo, los criterios últimos de validez del Derecho» ${ }^{70}$. La pretendida seguridad del tráfico jurídico inmobiliario no puede entenderse de un modo

69 Entre otras, véanse las resoluciones 9065/2015, de 18 de junio (RJ 2015\3731), y 5288/2016, de 7 de abril (RJ 201612987).

70 Atienza (2001: 213). 
tan extensivo como el planteado en la STC 28/2020, de 24 de febrero, ya que se estaría desnaturalizando el propio Registro de la Propiedad. No se puede obviar que la realidad social imperante en el momento de aprobación de la Ley Hipotecaria no es, ni de lejos, similar al momento actual. Además, la Constitución aparece como la norma jurídica suprema, de tal forma que el resto de normativa ha de ser examinada «a la luz» de sus mandatos (siendo los derechos fundamentales su máxima expresión).

Como señala el Fundamento Jurídico $4^{\circ}$ de la citada STC 28/2020, de 24 de febrero, a la hora de determinar el interés hemos de tener presente que no es cualquiera, pues ha de estar relacionado con el cumplimiento de la finalidad del registro, a saber, «la investigación jurídica, patrimonial y económica, que incluye el crédito, la solvencia y la responsabilidad de los titulares del inmueble». En todo caso, esta tarea no puede llevarse a cabo, tal y como pone de manifiesto el Tribunal, sin que medie una ponderación entre el interés del tercero y la injerencia en los derechos fundamentales de la persona a cuyo nombre figuren inscritos los bienes, «de modo que los datos que afecten a dichos derechos fundamentales, ya no van a poder figurar en el registro de la propiedad, operando en este caso el derecho a la cancelación».

Para finalizar, podemos concluir que los mandatos constitucionales y, en concreto, los derechos fundamentales de los individuos aparecen como una suerte de criterio de interpretación del ordenamiento jurídico, de tal forma que su contenido puede conllevar una variación (o, al menos, una moderación) del resultado al que debe llegar el jurista que se aproxima. De hecho, como se ha dejado apuntado y a pesar de no haber sido desarrollado por exceder de la finalidad pretendida, ello no ocurre únicamente con la vertiente formal del principio de publicidad, sino que opera, igualmente, en el seno del principio material, pudiendo llegar a corregir algún posicionamiento, precisamente, por la condición de uno de los sujetos y sus derechos subjetivos.

\section{Bibliografía}

Arias Grillo, R. (2008). La actividad cautelar en los procesos constitucionales de protección a los derechos fundamentales, control de constitucionalidad y conflictos de competencia. Revista de Ciencias Jurídicas, 116, 77-110.

Atienza, M. (2001). El sentido del Derecho. Barcelona: Ariel.

Barona Vilar, S. (2006). ¿Una nueva concepción expansiva de las medidas cautelares personales en el proceso penal?. Revista Poder Judicial, 19, 237-265.

Canales Gil, A. (2007). El derecho fundamental a la protección de datos de carácter personal. Revista jurídica de Castilla y León, 12, 13-56. 
Carpio Marcos, E. (2003). La interpretación de los derechos fundamentales. Derecho Pontificia Universidad Católica del Perú: Revista de la Facultad de Derecho, 56, 463-530. Disponible en: https://bit.ly/3b2UkA4.

Chocrón Giráldez, A. M. (2007). Tutela cautelar y protección de la víctima en el proceso penal. Boletin del Ministerio de Justicia, 2041, 7-23.

De Ángel Yagüez, R. (1990). La doctrina del «levantamiento del velo» de la persona juridica en la reciente jurisprudencia. Madrid: Civitas.

De Domingo Pérez, T. (2011). La teoría de la justicia del neoconstitucionalismo: los derechos fundamentales como núcleo del bien común. En A. L. Martínez Pujalte y T. de Domingo Pérez. Los derechos fundamentales en el sistema constitucional. Teoría general e implicaciones prácticas (pp. 5-30). Granada: Comares.

De Reina Tartière, G. (2012). El derecho registral inmobiliario y el Registro de la Propiedad. La notaría, 2, 49-66.

De Verda y Beamonte, J. R. (2014). El consentimiento de los menores e incapacitados a las intromisiones de los derechos de la personalidad. Actualidad jurídica iberoamericana, 1, 35-42.

Díez Picazo y Ponce de León, L. (2009). Fundamentos de Derecho civil patrimonial (vol. 3). Madrid: Civitas.

Faus, M. (2020). Los principios hipotecarios y su importancia práctica. Práctico Derecho Registral (vLex). Disponible en: https://bit.ly/3jmMh63.

Fernández Ballesteros, M. A. (2001). La ejecución forzosa y las medidas cautelares en la nueva Ley de Enjuiciamiento Civil, Madrid: Iurgilum.

Garberí Llobregat, J. (2016). El proceso de ejecución forzosa en la Ley de Enjuiciamiento Civil. Madrid: Civitas.

García García, J. M. (1993). Derecho Inmobiliario Registral o Hipotecario, Tomo II, el concepto de tercero, inoponibilidad, fe pública, prioridad. Madrid: Civitas.

- (1994). La función registral y la seguridad del tráfico inmobiliario. Revista Crítica de Derecho Inmobiliario, 70 (625), 2239-2310.

Giner García, J. J. (2014). Las medidas cautelares penales personales en el proceso penal español y su vinculación con los Derechos Fundamentales (especial referencia a las recomendaciones internacionales en materia de Derechos Humanos) [tesis doctoral]. Universidad Católica San Antonio de Murcia. Disponible en: https://bit. ly/3G7Mljz.

Gordillo Cañas, A. (2004). ¿Monismo o dualismo hipotecario? Hablen los autores del sistema. Anales de la Academia Matritense del Notariado, 42, 95-136.

Guichot, R. (2005). Datos personales y Administración pública. Cizur Menor, Navarra: Thomson-Civitas.

- (2005). Publicidad y privacidad de la información administrativa. Cizur Menor, Navarra: Thomson-Civitas.

Hermida Linares, M. (1966). La tradición y la inscripción en el Registro de la Propiedad como formas de adquirir los derechos reales sobre bienes inmuebles. Revista Critica de Derecho Inmobiliario, (457), 1401-1508.

Jiménez París, T. A. (2005). Los terceros de los artículos 32 y 34 de la Ley Hipotecaria. Madrid: Centro de Estudios Registrales. 
Lacruz Berdejo, J. L. y Sancho Rebullida, F. A. (1984). Derecho inmobiliario registral. Madrid: Bosch.

López Bustabad, I. J. (2018). El levantamiento del velo de la persona jurídica: una doctrina impredecible. Comentario a la STS de 14 diciembre 2017 (RJ 2017, 5811). Cuadernos civitas de jurisprudencia civil, 107, 141-158.

Martínez Martínez, R. (2007). El derecho fundamental a la protección de datos: perspectivas. IDP: revista de Internet, derecho y politica, 5, 47-51.

Miquel González, J. M. (1998). El registro inmobiliario y la adquisición de la propiedad. Revista Aranzadi de derecho patrimonial, 1, 45-62.

Moreno Catena, V. M. (2015). La fundamentación de las medidas cautelares y de las medidas de protección en el proceso penal. En R. Cuéllar Cruz (coord.). El valor de la democracia en la justicia: la exclusión de la prueba ilícita en el proceso penal y el respeto a los derechos fundamentales (pp. 173-202). República de Honduras: Universidad Tecnológica de Honduras: Ediciones Jurídicas Andrés Morales.

Núñez Lagos, R. (1949). El Registro de la Propiedad Español. Revista Crítica de Derecho Inmobiliario, 250, 137-171.

Rams Ramos, L. (2018). El derecho fundamental a la protección de datos de carácter personal como límite ¿(in)franqueable? para la transparencia administrativa. Estudios de Deusto: revista de la Universidad de Deusto, 66 (2), 119-152. Disponible en: https://bit.ly/3pD26JR.

Roca Sastre, R. M. (1965). El problema de la relación que respecto del artículo 34 Ley Hipotecaria guarda el artículo 32 de la misma. Revista Crítica de Derecho Inmobiliario, (pp. 781-830).

Sempere Navarro, A. V. (2020). Honor de empleado público absentista. (A propósito de la STS-CIV 382/2020 de 30 junio). Revista Aranzadi Doctrinal, 8, 1-9.

Valpuesta Fernández, R. (2005). Publicidad registral, seguridad del mercado y Estado social. Anuario de derecho civil, 58 (4), 1509-1574.

Warren, S. D. y Brandeis, L. D. (1890). The Right to Privacy. Harvard Law Review, 4 (5), 184-220. Disponible en: https://bit.ly/3aZ8KBm. 